\title{
Method to Determine the Electrical Energy for Ignition of Electro-Explosive Devices
}

\author{
Kameshwar Kumar Mishra, Aleti Sudheer Babu¹, Chandrakala P. Shetty¹, Himanshu Shekhar
}

\begin{abstract}
During field trials, it was observed that the delay of ignition of electro-explosive devices (EED) depends on ratings of power supplies or dynamo and also on the firing cable lengths. The change in ignition delay of EEDs due to altered supplied current will detoriate the repeatability of sequence of actions in time-critical armament applications. In order to study, supplement and analyze this observation, the measurement of electrical energy required for EEDs ignition is necessary. The electrical energy of EEDs has been determined experimentally by instrumentation and measurement setup using hall sensor and photo detector. The hall sensor is used to measure the actual current passing through EEDs when power supply is applied to them. Photo detector is used to detect the flash produced during EED ignition. By conducting repeated trials, it was observed that this method is reliable to determine the electrical energy required for EEDs ignition. With this parameter, the actual current to be supplied and the pulse width of supplied current for repeated ignition delays can be determined. Knowing the electrical energy of a particular EED by the proposed method, the required firing cable length and power supply for ignition of critical delay applications can be selected. This method also helps to design explosive-based ignition systems in defence applications.
\end{abstract}

KEYWORDS: Electro-explosive devices, Hall sensor, Photo detector, Electrical energy.

\section{INTRODUCTION}

Electro-explosive devices (EED) - an electric resistance encapsulated by a primary explosive - fundamentally convert electrical energy into thermal energy, from an explosive chemical reaction. EEDs are a class of pyrotechnics which include electrically initiated squibs, primers, pyro-cartidges, igniters, detonator, gas generators etc. (Jagtap et al. 2005; Danali et al. 2010). The design choice includes use of conducting composition like lead styphnate mixed with graphite, hot bridge wire, semiconductor-based bridge, exploding bridge wire, thin foil initiator etc. By coating an electric resistance with a thick layer of high-sensitivity explosive and applying an electric current to this circuit (bridge wire), the tiny explosive mass can certainly be thermally initiated (Austing et al. 1984; Rosenthal 1961).

During the trials, it was observed that EEDs of same type initiate after different time delays if levels of power supply and firing cable length are changed. With different firing cable lengths, the resistance of closed circuit from power supply to EED changes. This arrests the required current to EED, which changes the delay in ignition of EED. The duration the current is applied to EED determines the heating time of the bridge wire (Faria et al. 2012; Prince and Leeuw 1988; Pantoja et al. 2013). For measuring the current passing through EEDs, a hall sensor (Gokmen et al. 2008 ) is used. To detect the time of the ignition of EEDs, a photo detector (Kundu et al. 2012) is used, which is an optical receiver that converts light into electricity. When EEDs are initiated, the photo detector detects the flash produced by EED and gives the voltage proportional to the intensity of flash. This paper describes the instrumentation setup and transducers required to determine the electrical energy needed for ignition of EEDs. This parameter of electrical energy is required for development

1.Ministry of Defense - High Energy Materials Research Laboratory - Pune - India.

Author for correspondence: Aleti Sudheer Babu | High Energy Materials Research Laboratory | Sutarwadi - 411021 - Pune - India | Email: sudheerbabu_drdo@yahoo.co.in Received: 05/12/2015 | Accepted: 08/10/2015 
of new firing techniques of EEDs (Ziegler 1987) and also helps to ascertain the repeatability in critical delay applications of defence devices (Rosenthal 1961; Wilson and Hancox 2001).

\section{EXPERIMENTAL SETUP}

For the proposed method, a cylindrical test jig is designed. This test jig has the external electrical connections to connect the EED. One end of the test jig is provided with an optical window, which helps to pass the flash light of EED during ignition. The experimental setup is shown in Fig. 1. For this test, a general purpose squib with single nichrome wire bridge is used. A programmable power supply is used to vary supplied voltage and current levels in firing cable. Hall sensor (Current Transducer HA200 to 500-SB model which gives $10 \mathrm{~V}$ for $200 \mathrm{~A}$, Make-LEM components) is placed around the conductor carrying supply voltage according to direction of current. Photo detector (BPY-12, Silicon-PIN-Photodiode, spectral wavelength: 400 - 1,100 nm) is placed as near as possible in front of the window to compensate the ambient light. The output signals of hall sensor, photodiode and supply voltage are connected to an oscilloscope (Yokogawa make, DL750 model). On the oscilloscope, the signals are monitored with respect to time.

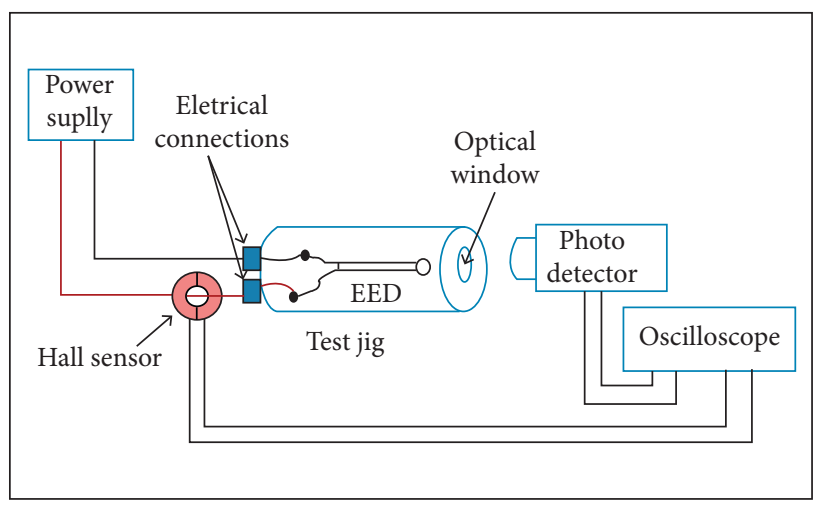

Figure 1. Experimental setup to determine the electrical energy for ignition of EEDs.

\section{TESTING PROCEDURE}

Initially, the resistance $(R)$ of EED bridge wire is measured using a safety ohmmeter. According to the resistance, the power supply voltage is changed for the required current level. After setting the voltage level, EED is connected to electrical connections of the test jig, placed inside it and power is supplied to EED. Once the power supply is switched on, the supplied voltage and the actual supplied current $i$ passing through the conductor can be monitored and measured on oscilloscope. After certain time, the rise of photo detector output signal will be detected on oscilloscope denoting the start time of EED ignition. The output signals monitored with respect to time on oscilloscope are shown in Fig. 2.

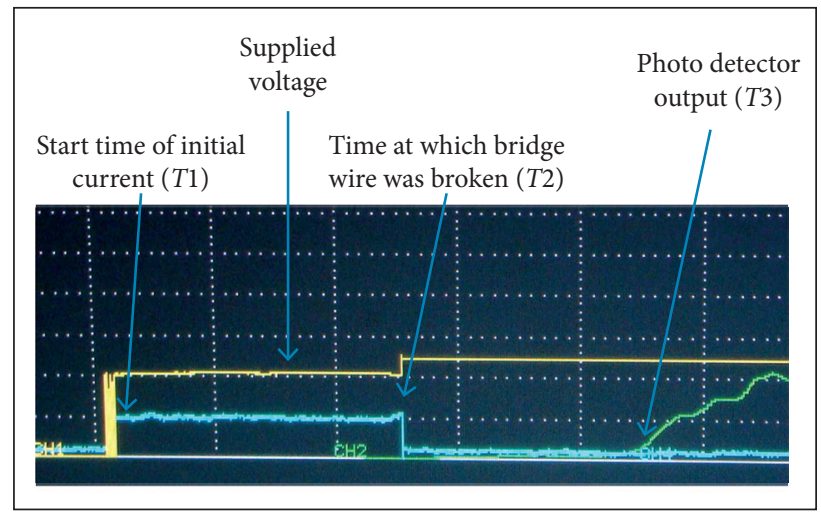

Figure 2. Supply voltage, current, and photo detector signals monitored on oscilloscope.

In Fig. 2, T1 is the time at which the current supply started, $T 2$ is the time at which bridge wire in EEDs breaks and T3 is the photo detector pulse indicating the start of EED ignition. T3 is considered at the knee point of rising signal of photo detector output. The time difference between EED ignition, i.e. the detection of photo detector pulse, and starting time of current pulse is considered as $t$ to calculate the actual energy for EED ignition using Eq. 1 (Ziegler 1987).

Electrical energy $=i^{2} \times R \times t$

where:

$i$ is the current passing through EED measured using hall sensor; $R$ is the EED bridge resistance measured with safety ohmmeter; and $t$ is the time for which electrical energy is supplied.

While conducting the experiments, the observation was made in some EEDs bridge wire breaks (detected from hall sensor) before or after the ignition (detected from photo detector) at certain supplied current levels. So, we considered two cases for $t$ in determining electrical energy levels:

- $\quad$ Case 1: bridge wire breaks before the ignition $(T 2<T 3)$ : in this case, the time for which the actual energy is supplied to EED is the difference between the time at which current supply started and the time at which the 
bridge wire in EEDs breaks. The monitored signals for this condition are shown in Fig. 3.

In Fig. 3, T1 is the time at which the current supply started, $T 2$ is the time at which bridge wire in EEDs breaks (denoting that current levels through EED become zero), and T3 is the photo detector pulse indicating the start time of EED ignition. For this case, time $t$ in Eq. 1 is $T 2-T 1$.

- $\quad$ Case 2: bridge wire breaks after the ignition $(T 2>T 3)$ : in this case, the time for actual energy supplied to EED is the difference between the time at which the current supply started and the time at which EED ignition started. The monitored signals for this condition are shown in Fig. 4.

In Fig. 4, $T 1$ is the time at which the current supply started, $T 2$ is the time at which bridge wire in EEDs breaks, and T3 is the photo detector pulse indicating the start time of EED ignition. For this case, time $t$ in Eq. 1 is T3 - T1.

\section{IGNITION ENERGY CALCULATION}

Using measured EED bridge resistance $(R)$ and current $(i)$ supplied through EED, the energy for EED ignition is calculated through Eq. 1 by considering time $t$ as T2 - T1 for Case 1 and $T 3$ - $T 1$ for Case 2.

\section{EXPERIMENTAL RESULTS}

Using the proposed method, 100 experiments were conducted, 20 of which at particular current levels of 1.05; $1.32 ; 2.04 ; 2.74$ and $3.44 \mathrm{~A}$. In these tests, we considered the squibs qualitatively proved (resistance check) before conducting the tests. So, dud squibs were not found during the experiments. In this study, we considered the EEDs with bridge resistance of $2.1 \pm 0.1 \Omega$ and varied the supplied voltage levels for required current as per squib resistance. We conducted the tests at various current levels and determined the electrical energy for EEDs ignition (general purpose squib) using Eq. 1. The average results of the tests are shown in Table 1 and are plotted as shown in Fig. 5.

From Fig. 5, it is clear that higher values of supplied current reduce time delay of ignition. Higher values of supplied current correspond to lower electrical energy and lower ignition delay. However, the curve seems to be asymptotic on either side. A very large supply of electrical energy may not reduce ignition delay to zero and a low energy supplied for infinite time may not lead to ignition. In Fig. 5, any electrical energy and time combination

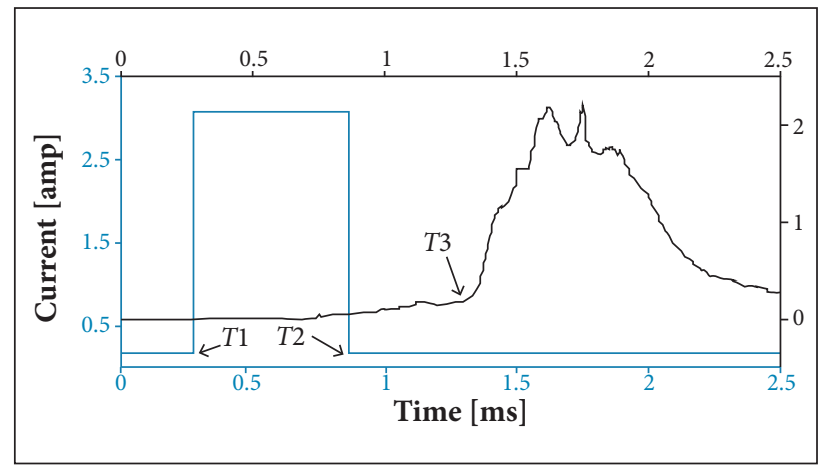

Figure 3. Supply voltage, current, and photodetector signals when bridge wire breaks before the ignition.

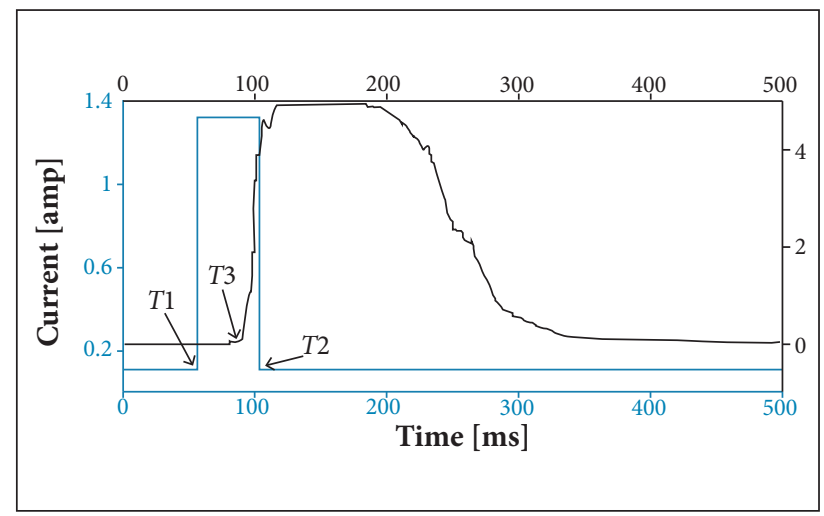

Figure 4. Supply voltage, current, and photodetector signals when bridge wire breaks after the ignition.

Table 1. Experimental results of electrical energy levels for ignition of EEDs at different current levels.

\begin{tabular}{|c|c|c|c|c|c|}
\hline $\begin{array}{l}\text { Current i } \\
\text { (A] }\end{array}$ & $\begin{array}{l}\text { Resistance } \\
\text { [ } \Omega]\end{array}$ & $\begin{array}{c}\text { Time at which bridge wire } \\
\text { breaks - } T 2 \text { (ms) }\end{array}$ & $\begin{array}{l}\text { Time at which photo detector } \\
\text { signal is received - } 73 \text { (ms] }\end{array}$ & $\underset{[\mathrm{ms}]}{\Delta \mathrm{t}}$ & $\begin{array}{l}\text { Electrical energy } \\
\text { [mJ] }\end{array}$ \\
\hline 1.05 & 2.135 & 45.188 & 23.708 & 23.708 & 55.80 \\
\hline 1.32 & 2.05 & 9.98 & 8.678 & 8.678 & 31.00 \\
\hline 2.04 & 2.2 & 2.102 & 5.19 & 2.102 & 19.25 \\
\hline 2.74 & 2.0 & 1.132 & 6.58 & 1.132 & 16.99 \\
\hline 3.44 & 2.18 & 0.572 & 1.852 & 0.572 & 14.76 \\
\hline
\end{tabular}


which lies above the plotted curve will definitely lead to ignition while any combination lying between axes and the curve leads to non-ignition. A compromise on high electrical energy at lower current level has to be arrived at, practically.

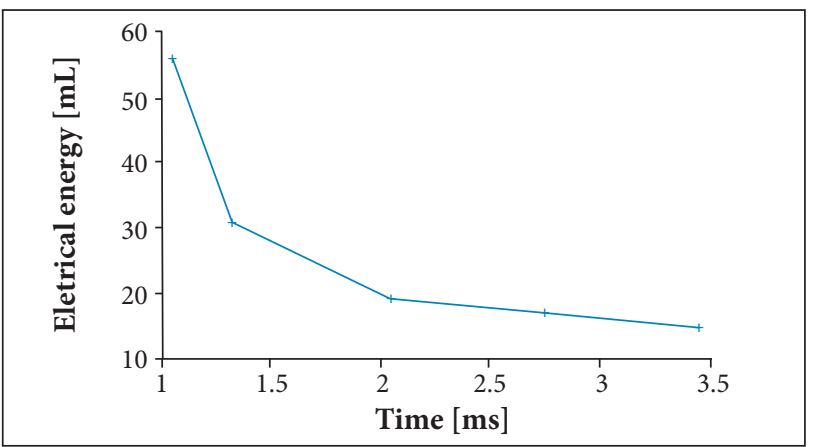

Figure 5. Energy levels at various supplied current levels.

\section{CONCLUSION}

This experiment is used to find the electrical energy required for the ignition of a particular EED type. This method helps to determine the minimum or maximum energy required for ignition of various EEDs used in different applications of armament. Observations found that the ignition delay varies with electrical energy. Finding the relationship between ignition delay and electrical energy will be the future scope of this study. It concludes that, by knowing the electrical energy levels through the proposed method, the ignition system voltage, current levels, and duration of power supply can be decided, which helps in designing various EED ignition systems. The threshold combination of electrical energy and duration is established for a particular type of suitable squibs/EEDs in this paper and a method for this is also provided.

\section{REFERENCES}

Austing لاL, Tulis AJ, Schmitt HR, Urbanski E, Mosora JA, Hawley J (1984) Electrothermal analysis as a tool for designing electric detonator firing circuits. Propell Explos Pyrot 9(6):193-200. doi: 10.1002/prep. 19840090604

Danali SM, Palaiah RS, Raha KC (2010) Development in pyrotechnics. Defence Sci J 60(2):152-158.

Faria PCC, Iha K, Rocco JAFF (2012) An analysis of the initiation process of electro-explosive devices. J Aerosp Technol Manag 4(1): 45-50. doi: 10.5028/jatm.2012.04015211

Gokmen G, Ozel Y, Ekren N (2008) Hall effect sensor and artificial neural networks application in current transformer. Int J Circ Syst Signal Proc 2(1):42-49.

Jagtap SS, Ghatak CK, Kohadkar MJ, Raha K, Subananda RA (2005) Pyrocartridges with $1 \mathrm{~A}-1 \mathrm{~W}$ no fire initiator. Proceedings of 5th International High Energy Materials Conference and Exibit (HEMCE-2005); Hyderabad, India.
Kundu D, Sarker DK, Hasan G, Podder PK, Rahman M (2012) Performance analysis of an InGaAs based PIN photodetector. Int J Soft Comput Eng 2(1):316-321.

Pantoja JJ, Peña NM, Rachidi F, Vega F, Roman F (2013) Susceptibility of electro-explosive devices to microwave interference. Defence Sci J 63(4):386-392. doi: 10.14429/dsj.63.2434

Prince WC, Leeuw MW (1988) Analysis of the functioning of the bridge wire igniters based on filled wire model. Propell Explos Pyrot 13(4):120-125.

Rosenthal LA (1961) Thermal response of bridge wire used in electro explosive devices. Rev Sci Instrum 32(9):1033-1036.

Wilson MA, Hancox RJ (2001) Pyrotechnic delays and thermal sources. J Pyrot 13:9-30.

Ziegler $K$ (1987) New developments in the field of firing techniques. Propell Explos Pyrot 12(4):115-120. doi: 10.1002/ prep.19870120402 